\title{
Mortality from amyloidosis and renal diseases in patients with rheumatoid arthritis
}

\author{
MARKKU LAAKSO ${ }^{1}$ OLLI MUTRU ${ }^{1}$ HEIKKI ISOMÄKI ${ }^{2}$ AND \\ KALEVI KOOTA ${ }^{2}$
}

From the ${ }^{1}$ Department of Medicine, Kuopio University Central Hospital, Kuopio, Finland; and the ${ }^{2}$ Rheumatism Foundation Hospital, Heinola, Finland

SUMmary Patients with rheumatoid arthritis (RA), 500 men and 500 women, aged 40 years and over, together with a control population matched by age and sex, were observed over a 10 year period. The overall mortality was significantly higher in both men and women with rheumatoid arthritis than in the controls due to an excess mortality from infections and cardiovascular and renal diseases. During the follow up 31 patients with RA (12 male, 19 female) and one male control subject died from amyloidosis and 42 RA patients (19 male, 23 female) and one male control from renal diseases. The most important causes of renal deaths were chronic nephritis and renal infections.

Life expectancy in patients with rheumatoid arthritis (RA) is markedly shortened as compared with that of subjects without RA. ${ }^{1-9}$ The important causes of death in patients with RA are secondary amyloidosis and renal diseases. ${ }^{12} 4$ 8-11 In previous studies no detailed analyses have been reported, however, on different renal diseases leading to death, mainly because of the small number of deaths due to renal disease.

We have carried out a 10 year prospective study to assess the mortality and causes of death in a cohort of 1000 subjects with RA and 1000 subjects without RA. The results of this study on total mortality and the specific causes of mortality according to the broad main categories of disease have been reported previously. ${ }^{12}$ The main causes of the excess mortality of patients with RA were infections and cardiovascular and renal diseases. This report deals in detail with the results concerning the mortality from amyloidosis and renal diseases in patients with RA and subjects without RA.

\section{Patients and methods}

A random sample comprising 500 men and 500 women, born 31 May 1930 or earlier and alive on 31 May 1970, was taken from among the patients with definite RA treated at the Rheumatism Foundation

Accepted for publication 29 January 1986.

Correspondence to Dr Markku Laakso, Department of Medicine, Kuopio University Central Hospital, 70210 Kuopio 21, Finland.
Hospital, Heinola, Finland during the years 195968. The diagnosis was based in every case on an examination at the hospital and the American Rheumatism Association criteria for RA. A sex and age matched ( \pm one year) cohort of 500 male and 500 female control subjects was randomly selected from the National Social Security Code Register comprising the whole Finnish population. None of the controls had RA, ankylosing spondylitis, or chronic systemic connective tissue disease at the beginning of the follow up. Details of the collection of data have been previously reported. ${ }^{12}$ Two male and nine female subjects without RA developed rheumatoid arthritis during the 10 year follow up, and these subjects were excluded from further analyses. The age at the beginning of the follow up was $54.5 \pm 0.4$ years (mean $\pm S E M$; range 40-87 years) for male RA patients and $55 \cdot 1 \pm 0.4$ years (range 40-87 years) for male controls. The corresponding ages for female RA patients were $55 \cdot 5 \pm 0 \cdot 4$ years (range 40-80 years) and for female controls $56 \cdot 2 \pm 0 \cdot 4$ years (range $40-80$ years) respectively.

A 10 year follow up of both cohorts with respect to mortality was carried out on the basis of a computer file of the official death certificates kept by the Central Statistical Office of Finland. The underlying cause of death as coded in the death certificates was used in the present analyses. The classification of causes of deaths from amyloidosis and renal diseases was based on the eighth version of the International Classification of Diseases. 
Survival statistics for amyloidosis and renal diseases were calculated using the so called D algorithm of Lee and Desu. ${ }^{13} \mathrm{D}$ is asymptotically distributed as $\chi^{2}$ with $(g-1)$ degrees of freedom, where g equals the number of groups, under the null hypothesis that the subgroups are samples from the same survival distribution. When $\mathrm{D}$ was calculated for certain diagnoses subjects dying from other causes were classified as censored observations for the rest of the 10 year follow up.

\section{Results}

Table 1 shows the number of deaths from amyloidosis and renal failure in subjects with RA and without RA classified by sex. During the 10 year follow up period altogether $208(42 \%)$ of the male subjects with RA and $144(29 \%)$ of the male subjects without RA died. The corresponding number of women was $148(30 \%)$ and $73(15 \%)$ respectively. The overall mortality was significantly higher in RA patients than in controls ( $p<0.001$ for both sexes). An excess of death in male RA patients was observed from infections $(p=0.048)$, cardiovascular diseases $(p<0.001)$, and from amyloidosis $(p<0.001)$, and from other causes of renal failure $(p<0 \cdot 001)$. In female RA patients an excess of death was observed

Table 1 Number of deaths from amyloidosis, renal failure, and other causes in subjects with $\left(R A^{+}\right)$and without $\left(R A^{-}\right)$rheumatoid arthritis classified by sex

\begin{tabular}{|c|c|c|c|c|}
\hline \multirow[t]{3}{*}{ Cause of death } & \multicolumn{4}{|c|}{ Number of subjects } \\
\hline & \multicolumn{2}{|l|}{ Men } & \multicolumn{2}{|c|}{ Women } \\
\hline & $\begin{array}{l}R A^{+} \\
(500)\end{array}$ & $\begin{array}{l}R A^{-} \\
(498)\end{array}$ & $\begin{array}{l}R A^{+} \\
(500)\end{array}$ & $\begin{array}{l}R A^{-} \\
(491)\end{array}$ \\
\hline Amyloidosis & 12 & 1 & 19 & 0 \\
\hline Renal failure & 19 & 1 & 23 & 0 \\
\hline Other causes & 177 & 142 & 106 & 73 \\
\hline Total & 208 & 144 & 148 & 73 \\
\hline
\end{tabular}

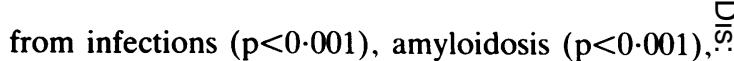
and from renal diseases $(\mathrm{p}<0.001)$. The proportion $\overrightarrow{\vec{F}}$ of deaths from amyloidosis was $5 \cdot 8 \%$ among male RA patients, $12 \cdot 8 \%$ among female RA patients, and $0.7 \%$ among male controls. The proportion of $\overline{\bar{c}}$. deaths from renal failure (amyloidosis excluded) was $9.1 \%$ among male RA patients, $15.5 \%$ among female RA patients, and $0.7 \%$ among male $\mathrm{e}^{\infty}$ controls. None of the female controls died from $\vec{\circ}$ amyloidosis or from other causes of renal failure. $\overrightarrow{-}$

Table 2 shows the age at the beginning of the ${ }_{0}^{\omega}$ follow up period and at the time of death ing deceased RA patients classified by sex. Female RA? patients dying from amyloidosis or from otherct causes of renal failure were younger than RA. patients dying from cardiovascular causes or from allo causes. In male RA patients no difference in age between subjects dying from amyloidosis or renal 5 diseases and other causes of death was observed.

Table 3 Death from amyloidosis and causes of death from renal failure in subjects with $\left(R A^{+}\right)$and without $\left(R A^{-}\right)$ rheumatoid arthritis in men

\begin{tabular}{llcll}
\hline & $I C D 8^{*}$ & $R A^{+}$ & $R A^{-}$ & $p^{+}$ \\
\hline Amyloidosis & 276 & $12(4+4)^{\ddagger}$ & $1(0+1)$ & $<0 \cdot 001$ \\
Nephritis acuta & 580 & $1(0+0)$ & 0 & NS \\
$\begin{array}{l}\text { Nephritis chronica } \\
\text { Nephritis NUD }\end{array}$ & 583 & $13(1+1)$ & 0 & $<0 \cdot 001$ \\
$\begin{array}{l}\text { Sclerosis renalis } \\
\quad \text { NUD }\end{array}$ & 584 & $1(0+1)$ & 0 & NS \\
$\begin{array}{l}\text { Infectio renis } \\
\text { Calculus renis et }\end{array}$ & 590 & $2(2+0)$ & 0 & NS \\
$\quad$ ureteris & 592 & $1(0+0)$ & 0 & NS \\
$\begin{array}{c}\text { Mb. renis et } \\
\quad \text { ureteris alia }\end{array}$ & 593 & 0 & $1(1+0)$ & NS \\
\hline
\end{tabular}

*The eighth version of the International Classification of Diseases. 'Significance of the D algorithm of Lee and Desu; NS=not $\dot{\rho}$ statistically significant.

†The first number in parentheses indicates the number of cases in whom an autopsy was performed; the second number indicates the 음 number of cases in whom a histological verification of amyloidosis or the cause of renal failure leading to death was obtained during the patient's lifetime.

Table 2 Age at the beginning of follow up and at death in deceased subjects with rheumatoid arthritis classified by sex and by cause of death

\begin{tabular}{|c|c|c|c|c|}
\hline \multirow[t]{2}{*}{ Cause of death } & \multicolumn{2}{|c|}{ Age (years) at the beginning of follow up } & \multicolumn{2}{|c|}{ Age (years) at the time of death } \\
\hline & Men & Women & Men & Women \\
\hline $\begin{array}{l}\text { Amyloidosis or renal diseases } \\
\text { Cardiovascular diseases } \\
\text { All causes }\end{array}$ & $\begin{array}{l}56 \cdot 5 \pm 1 \cdot 5 \\
58 \cdot 7 \pm 0 \cdot 6 \\
58 \cdot 3 \pm 0 \cdot 6\end{array}$ & $\begin{array}{l}56 \cdot 4 \pm 1 \cdot 2^{*} \\
61 \cdot 0 \pm 1 \cdot 0 \\
59 \cdot 2 \pm 0 \cdot 7\end{array}$ & $\begin{array}{l}61 \cdot 2 \pm 1 \cdot 6 \\
63 \cdot 6 \pm 0 \cdot 7 \\
63 \cdot 2 \pm 0 \cdot 6\end{array}$ & $\begin{array}{l}61 \cdot 4 \pm 1.2^{*} \\
65 \cdot 6 \pm 1 \cdot 1 \\
64 \cdot 0 \pm 0 \cdot 7\end{array}$ \\
\hline
\end{tabular}

Results are given as mean \pm SEM. Comparison with respect to age, by Student's two tailed $t$ test for independent samples, between subjects dying from amyloidosis or renal diseases and those dying from cardiovascular disease or all causes classified by sex. * $\mathrm{p}<0.01$ 
Male RA patients who died from amyloidosis or renal disease had suffered from RA for, on average, $16 \cdot 1$ years (range $8-33$ years) and $14 \cdot 8$ years (range 5-36 years) respectively. The corresponding values for female RA patients were 21.6 years (range $15-40$ years) and $19 \cdot 2$ years (range $10-32$ years).

Tables 3-5 show the causes of deaths from amyloidosis and renal failure in patients with and without RA classified by sex. Both the male and female RA patients died significantly more often from amyloidosis than the controls $(p<0 \cdot 001)$. The most important cause of death from renal failure both in men and women was chronic nephritis. In men other causes of death from renal diseases were uncommon, but female RA patients died more often

Table 4 Death from amyloidosis and causes of death from renal failure in subjects with $\left(R A^{+}\right)$and without $\left(R A^{-}\right)$ rheumatoid arthritis in women

\begin{tabular}{llrll}
\hline & $I C D 8^{*}$ & $R A^{+}$ & $R A^{-}$ & $p^{+}$ \\
\hline Amyloidosis & 276 & $19(7+5)^{\ddagger}$ & 0 & $<0.001$ \\
Nephritis acuta & 580 & $1(0+0)$ & 0 & NS \\
Nephritis chronica & 582 & $15(1+3)$ & 0 & $<0.001$ \\
Infectio renis & 590 & $7(3+0)$ & 0 & 0.007 \\
\hline
\end{tabular}

*The eighth version of the International Classification of Diseases. 'Significance of the D algorithm of Lee and Desu; NS=not statistically significant.

The first number in parentheses indicates the number of cases in whom an autopsy was performed; the second number indicates the number of cases in whom a histological verification of amyloidosis or the cause of renal failure leading to death was obtained during the patient's lifetime.

Table 5 Death from amyloidosis and causes of death from renal failure in subjects with $\left(R A^{+}\right)$and without $\left(R A^{-}\right)$ rheumatoid arthritis in both sexes combined

\begin{tabular}{llcll}
\hline & $I C D 8^{*}$ & $R A^{+}$ & $R A^{-}$ & $p^{+}$ \\
\hline Amyloidosis & 276 & $31(11+9)^{\ddagger}$ & $1(0+1)$ & $<0.001$ \\
Nephritis acuta & 580 & $2(0+0)$ & 0 & NS \\
Nephritis chronica & 582 & $28(2+4)$ & 0 & $<0.001$ \\
$\begin{array}{l}\text { Nephritis NUD } \\
\text { Sclerosis renalis }\end{array}$ & 583 & $1(0+1)$ & 0 & NS \\
$\quad$ NUD & 584 & $1(0+0)$ & 0 & NS \\
$\begin{array}{l}\text { Infectio renis } \\
\text { Calculus renis et }\end{array}$ & 590 & $9(5+0)$ & 0 & 0.002 \\
$\quad$ ureteris & 592 & $1(0+0)$ & 0 & NS \\
$\begin{array}{c}\text { Mb. renis et } \\
\text { ureteris alia }\end{array}$ & 593 & 0 & $1(1+0)$ & NS \\
\hline
\end{tabular}

* The eighth version of the International Classification of Diseases. 'Significance of the D algorithm of Lee and Desu; NS=not statistically significant.

FThe first number in parentheses indicates the number of cases in whom an autopsy was performed; the second number indicates the number of cases in whom a histological verification of amyloidosis or the cause of renal failure leading to death was obtained during the patient's lifetime. from renal infections than female controls $(p=0 \cdot 007$, Table 4$)$. When both sexes were analysed together the RA patients died more often from amyloidosis $(p<0 \cdot 001)$, chronic nephritis $(p<0.001)$, and from renal infections $(p=0 \cdot 002)$.

\section{Discussion}

Our results based on 1000 RA patients treated at the Rheumatism Foundation Hospital, Heinola, Finland and on 1000 subjects without RA confirmed the findings of several previous reports that the overall mortality and mortality from renal diseases were higher in patients with RA than in subjects without RA. ${ }^{1-9}$ We also found an excess of deaths from infectious and cardiovascular diseases in RA patients as compared with the corresponding controls. ${ }^{12}$

In only a few follow up series published so far has the number of deaths from amyloidosis been reported, mainly because these studies have been based only on a small number of patients. Prior et al found only three cases $(1.5 \%$ of all deaths) of amyloidosis in a study of 489 consecutive patients with definite or classical RA followed up for a mean of 11.2 years. ${ }^{11}$ Vandenbroucke et al reported five deaths $(3 \cdot 2 \%)$ from amyloidosis in a series of 209 patients of a 25 year prospective follow up study. ${ }^{9}$ In our series secondary amyloidosis was the cause of death more often than in previous studies. Twelve men $(5 \cdot 8 \%$ of all deaths) and 19 women $(12 \cdot 8 \%)$ with RA but only one male control $(0.7 \%)$ and none of the female controls died from amyloidosis. In $65 \%$ of all deaths from amyloidosis the diagnosis was based either on histological verification of the disease during the lifetime or on autopsy. In a postmortem series higher prevalence rates for amyloidosis have been reported. Mutru $e t$ al found seven cases $(17 \%)$ of amyloidosis in 41 patients with RA in a study consisting of 3115 autopsied patients. ${ }^{14}$ Missen and Taylor in their analysis of nine previous postmortem series of patients with RA calculated that the mean prevalence of amyloidosis in those studied was $15.9 \% .{ }^{15}$ Thus the contribution of amyloidosis to mortality is presumably greater than indicated by the death certificates.

The causes of death from renal failure (amyloidosis excluded) are reported only in a few previous studies. Prior et al found six deaths from the genitourinary system, three deaths being attributed to nephritis and three to renal calculus. ${ }^{11}$ Allebeck reported 20 deaths from urogenital diseases (five men, 15 women) in his study of 1165 RA patients followed up for up to seven years, but the cause of renal disease death was not described in detail. ${ }^{8}$ In our series the majority of deaths from renal disease 
in RA patients were due to chronic nephritis leading to uraemia. In female RA patients renal infections were also significantly more common than in the corresponding controls.

The high mortality from renal diseases in RA patients may be due to rheumatoid arthritis itself, to the mode of treatment, or to both. Secondary amyloidosis is likely to occur in severe or chronic forms of the disease independently of any medication, ${ }^{16}$ leading invariably to nephrotic syndrome and progressive uraemia. The cause of other renal diseases is even more difficult to ascertain. Renal side effects of drugs used in the treatment of RA patients have been seriously considered as an explanation for the high frequency of renal failure in RA. ${ }^{17}$ Gold and penicillamine both have severe renal side effects. ${ }^{18-22}$ In a recent series of 325 patients with RA followed up over a 5 year period Bourke et al reported that the prevalence of proteinuria in patients treated with D-penicillamine was $14 \cdot 1 \%$ and in patients treated with gold $9 \cdot 2 \% .{ }^{16}$ Persistent proteinuria was observed in 10 patients. Renal biopsies in these patients showed six cases of secondary amyloidosis, three cases of membranous glomerulonephritis in patients using D-penicillamine therapy, and one case of chronic interstitial nephritis. There is no evidence that treatment with gold or D-penicillamine leads to the development of amyloidosis, but the therapy with D-penicillamine has been shown to have a relationship with the development of membranous glomerulonephritis. ${ }^{22}$ Similarly, gold therapy has been reported to cause membranous glomerulonephritis. ${ }^{19} 21$ In addition, anti-inflammatory drugs may cause interstitial nephritis and papillary necrosis, leading to renal failure. $^{2324}$ Haematuria and mild mesangial glomerulonephritis have also been detected in patients with RA independently of drug therapy. ${ }^{25} 26$ A contributing factor leading to renal disease and death in RA may be subnormal resistance to infection, ${ }^{27}$ manifesting itself in our series as a high proportion of deaths from renal infection in female RA patients. Because of this complex inter-relationship between renal disease in RA itself and the possible role of different drug treatments in relation to the pathogenesis of renal failure we did not correlate the drug therapy of our RA patients with the mortality from amyloidosis or renal disease. Additional factors complicating the assessment of drug therapy in relation to renal disease are the incomplete documentation of the drugs used, the possibility of self administration of drugs, and several medicaments used in the therapy, each of which may contribute to the development of renal disease. ${ }^{17}$

In conclusion, this large scale, 10 year prospective cohort study comprising 1000 subjects with RA and $\frac{0}{\omega}$ 1000 subjects without RA shows that there is an excess of deaths from amyloidosis and renal diseases $\stackrel{\vec{s}}{+}$ in patients with RA. The main causes of deaths from 0 renal diseases in patients with RA were chronic $\bar{O}$ nephritis in both sexes and renal infections in female $\frac{\bar{p}}{\bar{\sigma}}$ RA patients.

\section{References}

1 Cobb S, Anderson F, Bauer W. Length of life and cause of death in rheumatoid arthritis. $N$ Engl J Med 1953; 249: 553-6. $\vec{\omega}$

2 Duthie J J R, Brown P E, Truelove L H, Baragar F D, Lawrie A J. Course and prognosis in rheumatoid arthritis: a further report. Ann Rheum Dis 1964; 23: 193-202.

3 Uddin J, Kraus A S, Kelly H G. Survivorship and death in is rheumatoid arthritis. Arthritis Rheum 1970; 13: 125-30.

4 Isomäki H, Mutru O, Koota K. Death rate and causes of death $\infty$ in patients with rheumatoid arthritis. Scand J Rheumatol 1975; ठु 4: $205-8$

5 Monson R R, Hall A P. Mortality among arthritics. J Chron Dis 윽 1976; 29: 459-67.

6 Koota K, Isomäki H, Mutru O. Death rate and causes of death $D$ in RA patients during a period of five years. Scand $J$ Rheumatol 1977; 6: 241-4.

7 Allebeck P, Ahlbom A, Allander E. Increased mortality among $\frac{\infty}{+}$ persons with rheumatoid arthritis, bút where RA does not $\overrightarrow{0}$ appear on the death certificates. Scand J Rheumatol 1981; 10: 301-6.

8 Allebeck P. Increased mortality in rheumatoid arthritis. Scand J Rheumatol 1982; 11: 81-6.

9 Vandenbroucke J P, Hazevoet H M, Cats A. Survival and cause of death in rheumatoid arthritis: a 25 -year prospective followup. J Rheumatol 1984; 11: 158-61.

10 Rasker J J, Cosh $\mathrm{J}$ A. Cause and age at death in prospective $(\mathrm{D}$ study of 100 patients with rheumatoid arthritis. Ann Rheum Dis 1981; 40: 115-20.

11 Prior P, Symmons D P M, Scott D L, Brown R, Hawkins C F. Cause of death in rheumatoid arthritis. Br $J$ Rheumatol 1984; 23: $92-9$

12 Mutru O, Laakso M, Isomäki $\mathrm{H}$, Koota $\mathrm{K}$. Ten year mortality and causes of death in patients with rheumatoid arthritis. $\mathrm{Br} \cong$ Med J 1985; 290: 1797-9.

13 Lee E, Desu M. A computer program for comparing k samples with right-censored data. Comput Programs Biomed 1972; 2 315-21

14 Mutru O, Koota K. Isomäki H. Causes of death in autopsied $\frac{\mathrm{O}}{3}$ RA patients. Scand J Rheumatol 1976; 5: $239-40$.

15 Missen G A K, Taylor J D. Amyloidosis in rheumatoid음 arthritis. J Pathol Bacteriol 1956; 71: 179-92.

16 Bourke B E, Woodrow D F. Scott J T. Proteinuria in O rheumatoid arthritis-drug-induced or amyloid? Ann Rheum Dis 1981; 40: 240-4.

17 Lawson A A H, Maclean N. Renal disease and drug therapy in 0 rheumatoid arthritis. Ann Rheum Dis 1966; 25: 441-9.

18 Vaamonde C A. Hunt F R. The nephrotic syndrome as a N complication of gold therapy. Arthritis Rheum 1970;13: 826-34. $\omega$

19 Blackwell M R, Hall C L, Tribe C R, Bacon P A. Gold induced nephropathy. Ann Rheum Dis 1981; 40: 525.

20 Hall C L. Gold- and D-penicillamine-induced renal disease. In: $\frac{C}{C}$ Bacon P A, Hadler $\mathbf{N}$, eds. The kidney and rheumatic disease. London: Butterworth Scientific, 1982: 246-66.

21 Silverberg D S, Kidd E G, Shnitka T K, Ulan R A. Gold nephropathy: a clinical and pathologic study. Arthritis Rheum? 1970; 13: 812-25.

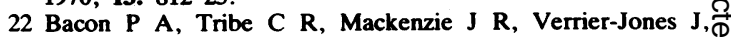
Cumming $\mathbf{R} \mathbf{H}$, Amer B. Penicillamine nephropathy in rheuma- $\mathrm{O}$ toid arthritis. $Q J$ Med 1976; 45: 661-84. 
23 Clive D M, Stoff J S. Renal syndromes associated with nonsteroidal anti-inflammatory drugs. $N$ Engl J Med 1984; 310: 563-72.

24 Clausen E, Pedersen J. Necrosis of the renal papillae in rheumatoid arthritis. Acta Med Scand 1961; 170: 631-3.

25 Hordon L D. Sellars L, Morley A R, Wilkinson R, Thompson $M$, Griffiths I D. Haematuria in rheumatoid arthritis: an association with mesangial glomerulonephritis. Ann Rheum Dis 1984; 43: 440-3.

26 Friedman R, Gallo G R, Buxbaum J N. Renal disease in rheumatoid arthritis. Arthritis Rheum 1980; 23: 781-3.

27 Baum J. Infection in rheumatoid arthritis. Arthritis Rheum 1971; 14: $135-7$. 